\title{
POR UMA ETNOGRAFIA DOS DADOS A propósito de uma investigação sobre o perfil social dos militares brasileiros
}

\author{
Celso Castro \\ Escola de Ciências Sociais da Fundação Getulio Vargas, Rio de Janeiro, Brasil

\section{Silvia Monnerat} \\ Escola de Ciências Sociais da Fundação Getulio Vargas, Rio de Janeiro, Brasil
}

\begin{abstract}
Resumo O objetivo deste artigo é mostrar como dados "brutos" (hard data) não são "neutros" nem "dados", mas estão inseridos num processo subjetivo de sua produção, manutenção e utilização. Propomos, aqui, descrever esse processo de "construção social dos dados" tendo como objeto dados obtidos junto a escolas militares brasileiras sobre o perfil social de seus alunos. A observação etnográfica dessas práticas permite ver como elas estabelecem princípios seletivos, iluminam certas dimensões da vida da instituição e obscurecem outras. Evita-se, assim, um "fetichismo dos dados": a tendência a vê-los como entidades com vida própria, independentes da subjetividade dos indivíduos que os produziram, os mantiveram e lhes deram acesso.
\end{abstract}

Palavras-chave: hard data, dados, objetos, militar, etnografia.

Abstract The purpose of this article is to show how hard data are not "neutral" or "given"; but are instead embedded in a subjective process of production, maintenance and utilization. We propose to describe this process of "social construction of data" by taking as object data obtained from Brazilian military schools on the social profile of their students. The ethnographic observation of these practices allows us to see how they establish selective principles, illuminating certain dimensions of the institution's life and obscuring others. Thus, a "data fetishism" is avoided: the tendency to see such data as entities with a life of their own, independent on the subjectivity of the individuals who produced them, maintained them and gave access to them.

Keywords: hard data, objects, military, ethnography

Résumé Le but de cet article est de montrer comment les données concrètes (hard data) ne sont pas "neutres" ou "données", mais sont intégrées à un processus subjectif de production, de maintenance et d'utilisation. Nous proposons ici de décrire ce processus de "construction sociale de données" avec des données obtenues auprès d'écoles militaires brésiliennes sur le profil social de leurs étudiants. L'observation ethnographique de ces pratiques nous permet de voir comment ils établissent des principes sélectifs, éclairent certaines dimensions de la vie institutionnelle et en obscurcissent d'autres. On évite ainsi un "fétichisme des données": la tendance à les considérer comme des entités autonomes, indépendantes de la subjectivité des individus qui les ont produites, les ont conservées et leur ont donné accès.

Mots-clés: hard data, données, objets, militaires, ethnographie.

Resumen El objetivo de este artículo es mostrar como datos "brutos" (hard data) no son "neutros" ni "datos", pero están insertos en un proceso subjetivo de su producción, mantenimiento y utilización. Proponemos, aquí, describir ese proceso de "construcción social de los datos" teniendo como objeto datos obtenidos junto a escuelas militares brasileñas sobre el perfil social de sus alumnos. La observación etnográfica de estas prácticas permite ver cómo establecen principios selectivos, iluminan ciertas dimensiones de la vida de la institución y oscurecen otras. Se evita, así, un "fetichismo de los datos": la tendencia a verlos como entidades con vida propia, independientes de la subjetividad de los individuos que los produjeron, los mantuvieron y les dieron acceso.

Palabras clave: hard data, datos, objetos, militar, etnografía 
Dados quantitativos "brutos" ou hard data muitas vezes são vistos por cientistas sociais como a base sólida sobre a qual se pode construir uma ciência mais precisa e rigorosa - ou, sem usar meias palavras, mais "científica". É claro que se sabe que os dados podem ser mais ou menos confiáveis e que sua disponibilidade obedece a variáveis de natureza social. Entretanto, uma mera crítica interna dos dados - em relação à sua confiabilidade e consistência - não impede que se desenvolva uma visão fundamentalmente naturalizada a seu respeito: de que eles, de alguma forma, "estão lá", em algum lugar, prontos para serem "coletados". Mais que isso, acredita-se que, uma vez conseguidos ou acessados, eles ganham vida independente do contexto social em que foram produzidos e mantidos e podem, desse modo, ser "trabalhados" com objetividade pelo cientista social.

Configura-se, assim, o que poderíamos chamar, inspirados numa imagem clássica de Marx, de um "fetichismo dos dados": vê-los como entidades com vida própria, independentes da subjetividade dos indivíduos que os produziram, os mantiveram e lhes deram acesso. Referimo-nos a uma atribuição de valor simbólico, que passa a instaurar relações sociais mediadas pela noção de que os dados possuem total autonomia e credibilidade, configurando-se como representantes verdadeiros dos fenômenos estudados.

À crítica interna dos dados achamos necessário, contudo, agregar uma perspectiva que também leve em conta processos subjetivos de várias ordens na sua constituição. Os dados não são "dados", no sentido de que não "estão lá" prontos para serem "acessados". Howard Becker (2007) ao fazer uma reflexão metodológica sobre a objetividade e a subjetividade inscritas em um objeto material, explicita:

Os objetos materiais, embora fisicamente reais, não têm propriedades “objetivas". [...]. Nós lhes atribuímos essas propriedades, por razões sociais, ao reconhecer que eles as possuem. Os sociólogos muitas vezes supõem que as propriedades físicas de um objeto restringem o que as pessoas envolvidas com ele podem fazer. Quase invariavelmente, porém, essas propriedades são restritivas se, e somente se, as pessoas usarem o objeto da maneira que todos reconhecem que ele é em geral usado. (Becker, 2007: 72)

Nossa experiência de pesquisa em escolas militares a respeito do perfil social de seus alunos nos levou a tratar os dados quantitativos por nós obtidos a partir dessa perspectiva proposta por Becker. Pudemos ver com clareza que os dados dependem de um processo subjetivo de sua produção, manutenção e utilização. Propomos, aqui, descrever esse processo de "construção social dos dados". Uma inspiração vem do estudo de Garnett (2015) que, ao examinar como são construídos dados sobre a poluição atmosférica, enfatiza as relações travadas em campo, o trabalho colaborativo entre diferentes instituições e a importância de que, durante o trabalho etnográfico, o pesquisador busque "seguir" os dados e a forma como eles foram construídos (por diferentes interlocutores e instituições). Assim sendo, a reflexão sobre como informações se transformam em dados é nosso próprio objeto de pesquisa nesse artigo. 
Descreveremos a seguir como os dados sobre o perfil social dos cadetes da Academia Militar das Agulhas Negras (AMAN) e da Escola Preparatória de Cadetes do Exército (EsPCEx) e dos alunos da Escola de Sargentos das Armas (EsSA) são tratados. ${ }^{1}$ Mostraremos como, durante o trabalho de "levantamento" dos dados, nos deparamos com descobertas que nos levaram a reorientar a pesquisa.

Para lidar com esse caso, seguimos um dos "truques" propostos por Becker e buscamos informações sobre "todas as indicações de como ele [o conjunto de dados] ficou daquela maneira, de quem fez o quê para que essa coisa exista agora desse modo" (Becker 2007: 76). Desse modo, verificaremos que os dados, assim como os objetos descritos por Becker, são "a encarnação física de todas as ações que todos praticaram para lhes dar existência". (Becker 2007: 72)

Nossa discussão estará centrada, portanto, na questão da subjetividade inscrita na formulação de dados quantitativos e na necessidade de uma descrição densa sobre as condições de existência desses dados para alcançar um entendimento mais acurado sobre as "teias de significado" imbricadas nos processos de sua produção.

\section{II}

Uma discussão já antiga nas ciências sociais brasileiras diz respeito à origem e ao perfil social dos militares. Impressões vagas a respeito do caráter mais "elitista" ou de "classe média" dos oficiais, ou de tendências históricas de mobilidade social ascendente ou descendente, ou mesmo uma suposta "proletarização" de seus quadros; de sua distribuição geográfica mais ou menos nacional ou, ao contrário, concentrada regionalmente; da maior convergência ou divergência em relação à sociedade brasileira em geral de características como religião e renda familiar, dentre outras, estiveram e estão presentes não apenas em estudos acadêmicos, como no discurso cotidiano dos próprios militares.

Deve-se observar, desde logo, que essa discussão, no Brasil, se concentra principalmente sobre o Exército, havendo pouca pesquisa e informação a respeito do que se passa nas outras duas forças (Marinha e Força Aérea). Além disso, fala-se muito mais sobre o perfil do corpo de oficiais, havendo pouquíssima informação a respeito das praças. ${ }^{2} \mathrm{O}$ fato de ter sido a maior força em termos numéricos, mas também a de maior protagonismo político na história do Brasil republicano certamente contribuiu para esse maior interesse dos cientistas sociais pelo Exército.

1 A EsPCEx, localizada em Campinas (estado de São Paulo), funcionou por décadas como uma escola preparatória de três anos correspondente ao ensino médio civil. Desde 2012 é considerada como o primeiro ano do curso de formação dos oficiais do Exército, completado em mais quatro anos na AMAN, localizada em Resende (estado do Rio de Janeiro) e equivalente a um curso universitário de nível superior. Já a EsSA, localizada em Três Corações (estado de Minas Gerais) forma, durante aproximadamente um ano, os sargentos das Armas bélicas do Exército (Infantaria, Cavalaria, Artilharia, Engenharia e Comunicações).

2 Militares das graduações inferiores na escala hierárquica da instituição militar. No Exército, corresponde aos soldados, cabos, sargentos e subtenentes. 
Quanto ao interesse privilegiado a respeito da oficialidade superior, sem dúvida ela se relaciona às características centrais da própria instituição militar, como a hierarquia e a disciplina, expressas cotidianamente numa clara cadeia de comando. Desse modo, os que estão no topo da escala hierárquica detêm mais poder institucional, característica que muitas vezes se projetou, na história, para um maior protagonismo político.

Não queremos de forma alguma minimizar a importância da Marinha ou da Força Aérea, nem das praças, para a compreensão da atuação dos militares na história republicana do Brasil. Essas duas outras forças e as praças também tiveram significativo protagonismo político em diferentes conjunturas históricas. A hegemonia do Exército e a manutenção do controle hierárquico da oficialidade sobre as praças tem sido, contudo, marcante desde a década de $1930 .{ }^{3}$

No caso da oficialidade do Exército, essa discussão ganhou importância acadêmica a partir do estudo pioneiro do cientista político norte-americano Alfred Stepan, que publicou em 1971 The Military in Politics: Changing Patterns in Brazil. ${ }^{4}$ Posteriormente, o tema foi tratado por pesquisadores como José Murilo de Carvalho, Alexandre Barros e Celso Castro. ${ }^{5}$ A discussão de fundo era com autores que viam as Forças Armadas quer como representantes de uma "classe média" vagamente definida, quer, numa perspectiva marxista, como instrumento de classe de setores da burguesia ou de grupos dominantes em geral, sem que fossem apresentadas evidências empíricas sólidas a respeito da composição social da oficialidade ou de seu processo de socialização profissional. Embora não houvesse consenso a respeito da importância e do impacto que essas características poderiam ter para o comportamento político das Forças Armadas, havia uma clara percepção, para os autores acima nomeados, de que era necessário situar a discussão em terreno empiricamente mais firme.

Não cabe aqui fazer a revisão desse debate. Apenas mencionamos sua existência para nele inserir o desejo que tínhamos de atualizar a discussão com novos dados, e mais complexos, a respeito do perfil e da origem social dos militares do Exército. Isso ocorreu no âmbito de um projeto denominado "Transformações da Profissão Militar no Brasil", desenvolvido na Escola de Ciências Sociais da Fundação Getulio Vargas (FGV CPDOC). Após o início da pesquisa, estabelecemos um convênio de cooperação acadêmica entre a FGV e o Estado-Maior do Exército (EME) que visava, dentre outros objetivos, facilitar a obtenção de dados a respeito do Exército.

Assinado o convênio, pedimos ao EME, através do coronel que era nosso principal contato na pesquisa, que solicitasse às escolas acima mencionadas as informações que queríamos. No caso da AMAN, Celso Castro já tinha familiaridade com a forma pela qual esses dados eram tabulados. Anualmente, os alunos ingressantes no

3 Para o conturbado quadro político da Primeira República, temos o seminal estudo de José Murilo de Carvalho (2005), capítulo “As Forças Armadas na Primeira República: o poder desestabilizador", originalmente publicado em 1978.

$4 \quad$ Uma tradução brasileira foi publicada pela editora Artenova, em 1975.

5 Ver Barros (1978), Carvalho (2005) e Castro (2004 [1990] e 1994). 
primeiro ano da AMAN (pouco depois, oficialmente chamados de "cadetes") preenchiam um questionário com informações pessoais que incluíam aquelas que mais nos interessavam: naturalidade, escolaridade anterior (se havia, por exemplo, estudado em colégio militar), profissão do pai (caso fosse militar, se oficial ou praça), profissão da mãe, renda familiar e religião. Essas informações eram agregadas e consolidadas num Anuário Estatístico produzido ininterruptamente ao menos desde o início da década de 1980, e que Celso Castro localizou durante sua pesquisa de campo realizada na AMAN entre 1986 e 1987. Alguns anos mais tarde, conseguiu obter esses anuários até 1991. Nesta segunda ocasião, pôde entrar em contato diretamente com os responsáveis pela tabulação dos dados, obtendo assim uma visão mais clara sobre as dificuldades de pessoal e a pequena capacidade operacional que tinham para fazer qualquer análise a respeito.

Somando-se os dados obtidos para o final dos anos 1980 e início da década de 1990 com dados apresentados por Alfred Stepan para alguns anos das décadas de 1940 e 1960, foi possível perceber, ao longo da série histórica, algumas tendências claras na modificação do perfil dos alunos da AMAN, consolidadas num artigo publicado em 1994 (Castro 1994). Dentre elas, para mencionar a mais significativa, estava uma crescente tendência ao recrutamento endógeno, isto é, o ingresso cada vez maior de filhos de militares.

Buscávamos agora, duas décadas depois, não apenas atualizar essa série histórica da AMAN como também, com a colaboração do EME, conseguir recuar o máximo possível no tempo e ainda obter bases de dados desagregados que permitissem o cruzamento estatístico das variáveis acima destacadas. Além disso, desejávamos também receber informações sobre o perfil dos sargentos formados na EsSA, até agora inéditos. É importante aqui notar que um pedido feito pelo Estado-Maior do Exército em relação a essas escolas vem de um nível hierárquico superior em relação aos comandos das escolas, e que, portanto, precisa ser respondido.

Como resultado, o EME nos encaminhou o material que recebeu: da AMAN, os arquivos ${ }^{6}$ dos Anuários Estatísticos desde 1981 (embora faltando alguns anos), com os dados já agregados, em formato PDF ou Word; da EsSA, dados sobre alguns anos mais recentes em formato Excel, mas também já agregados. Explicamos a situação ao nosso colaborador no EME, que contatou novamente as escolas pedindo mais informações e dados desagregados, porém não obteve sucesso. A resposta foi de que esses eram os dados e formatos disponíveis.

Diante desse quadro, pedimos para ir à AMAN conversar in loco com os responsáveis por esses dados. O objetivo era explicar melhor nossos interesses de pesquisa e assim tentar obter as informações que desejávamos. O EME prontamente agendou nossa visita à AMAN, indicando também quem deveríamos inicialmente contatar: o tenente-coronel responsável pela 1. ․ Seção (Corpo de Cadetes).

$6 \quad$ Ficheiros, em português de Portugal. 
III

A visita à AMAN ocorreu em 23/10/2015. ${ }^{7}$ Lá chegando, o tenente-coronel responsável por nos receber disse que o general comandante da AMAN gostaria de nos cumprimentar ao final da visita e encaminhou-nos à 1. - Seção do Corpo de Cadetes. ${ }^{8}$

Lá chegando, explicamos ao tenente que nos recebeu os motivos de nossa visita, mencionando o convênio firmado entre a FGV e o EME. Perguntamos sobre os dados relacionados ao perfil socioeconômico dos cadetes e se naquela seção seria possível encontrar esses dados de maneira desagregada, o que possibilitaria uma melhor análise. O tenente disse que essa seção era o "cérebro da academia", responsável por todas as questões relacionadas ao controle de pessoal, ingresso dos cadetes, sindicâncias e consolidação de dados tendo em vista o agrupamento de dados individuais dos cadetes e a elaboração do Anuário Estatístico. Mostrou-nos um questionário e tabelas no computador referentes ao seu trabalho, copiando imediatamente os arquivos para nossos dispositivos de armazenagem, e explicou que o objetivo deles naquela seção não estava relacionado à atividade de pesquisa e sim à feitura do anuário. Os dados eram tabulados a partir dos questionários que eram preenchidos pelos alunos ingressantes e repassados pelos comandantes de companhias à 1. ํㅗㄹ Seção; esta, além de arquivá-los, organizava o Anuário Estatístico.

O tenente enfatizou que, para evitar que pudesse ocorrer qualquer manipulação nas tabelas já finalizadas, elas eram salvas apenas em formato PDF, deletando-se o arquivo original. Disse, ainda, que ali "trabalhavam por demanda", isto é, apenas quando recebiam a ordem de fornecer determinado dado. Mencionou em particular uma demanda sobre a religião dos cadetes vinda recentemente do Comando do Exército e que, para ter maior precisão em relação aos dados, foi determinado que cada capitão comandante de companhia de alunos colocasse sua tropa em forma e quantificasse sua filiação religiosa, encaminhando o resultado para essa seção.

Os documentos e informações dos cadetes são arquivados em pastas físicas individuais na 1. - Seção, vindo a fazer futuramente parte do seu Livro de Alterações, espécie de curriculum vitae que acompanha cada oficial por toda a sua trajetória profissional, transitando pelas unidades em que serve, até sua passagem para a reserva. Disse-nos o tenente, em tom de brincadeira, que era preferível perder um fuzil do que uma pasta de cadete, pois ali estavam presentes todas as informações sobre o mesmo, muitas vezes únicas e dificilmente recuperáveis.

Pedimos para ver, como exemplo, alguns questionários em papel respondidos pelos ingressantes em 2015. O tenente abriu um arquivo de metal que continha as pastas em papel de todos os cadetes, porém, após pegar aleatoriamente várias

Além dos autores, esteve presente também Márcio Grijó Vilarouca (FGV/CPDOC).

A AMAN se divide em quatro setores: Corpo de Cadetes, Corpo Administrativo, Corpo de Serviços e Divisão de Ensino. Esta está subdividida, por sua vez, numa Seção de Ensino e numa Coordenação Pedagógica, responsável pelas subseções de Planejamento, de Pesquisa, de Acompanhamento Pedagógico e de Avaliação da Aprendizagem. Ver http://www.aman.ensino.eb.br/. 
pastas, não encontrou nenhum questionário do ano corrente. Perplexo, levantou a hipótese de o questionário não ter sido aplicado em 2015, embora afirmasse que "teoricamente, deveriam estar" ali. Perguntamos se a aplicação do questionário, caso não tivesse mesmo ainda sido feita em 2015, ainda o seria, e o tenente respondeu que, se o questionário não tivesse sido aplicado no começo do ano, provavelmente não o seria mais.

Um capitão que também servia nessa seção e acompanhara de longe nossa conversa tentou igualmente achar os questionários dos cadetes referentes ao ano de 2015 nas pastas dispostas no arquivo, mas não os encontrou, o que causou um certo constrangimento, pois ninguém ali sabia que o documento não constava no arquivo, e tampouco tinham certeza se ele havia sido ou não aplicado e, caso tivesse sido, onde estaria. Esse capitão e um outro tenente que acompanhara de longe nossa conversa nos falaram então sobre a existência de arquivos apelidados de "tripão", que conteriam todas as informações dos cadetes, incluindo as que desejávamos obter. Segundo eles, tratava-se de uma planilha (em formato Excel), sob responsabilidade do capitão comandante de cada companhia.

Seguimos, então, para a Coordenação Pedagógica, parte da Divisão de Ensino, acompanhados pelo capitão da 1. - Seção que mencionou a existência do "tripão". Fomos recebidos por dois majores e explicamos novamente nossos interesses de pesquisa e a vinculação do projeto com o convênio firmado com o EME. Ali nos explicaram que na AMAN só é feita uma entrevista com os cadetes ingressantes, e que os dados socioeconômicos que buscávamos não eram o alvo dessa entrevista, e sim o "nível de desenvolvimento acadêmico e emocional dos cadetes". Segundo eles, essa abordagem "afetiva" proporcionava um "estreitamento de laços" entre o comandante e o cadete.

Esses oficiais disseram também que a EsPCEx possui um banco de dados com informações sobre os cadetes, mas que eles não correspondiam integralmente à realidade da AMAN, pois sempre ocorre uma evasão na passagem de uma turma da EsPCEx à AMAN. Mencionaram que no ano de 2011 a evasão havia sido de quase $20 \%$ (cerca de 90 em 480 cadetes) mas que não tinham clareza sobre o que teria acontecido, levantando a hipótese de que, quando a EsPCEx passou a ser considerada o primeiro ano do curso de formação de oficiais, a exigência tenha se tornado maior, aumentando consequentemente a evasão. Eles disseram, no entanto, que teriam interesse em uma pesquisa sobre as causas dessa evasão, para que pudessem entender melhor os motivos de quem desistia da carreira militar depois de já ter cursado um ano. Disseram, ainda, que possuíam dificuldades práticas para realizar uma pesquisa desse tipo, tanto por falta de pessoal quanto de uma cultura de pesquisa na instituição, e foi sugerido que eventualmente nós poderíamos assumir a tarefa.

Da Coordenação Pedagógica seguimos, acompanhados pelo mesmo capitão que agora desempenhava o papel de nosso "guia", até a 1. ․ Companhia do Curso Básico, correspondente ao primeiro ano do curso da AMAN, onde encontraríamos o exemplo de "tripão" que ele mencionara. Lá fomos recebidos pelo capitão comandante, a quem expusemos novamente os interesses da pesquisa e mencionamos o convênio com o EME. O capitão então nos explicou claramente o porquê de 
não termos achado os questionários nas pastas localizadas na 1. - Seção do Corpo de Cadetes: os questionários desse ano em curso encontravam-se ainda em cada Companhia, e só iriam para a 1. - Seção ao final do ano. Ele tinha consigo os dados de todos os 119 cadetes pelos quais era responsável (sendo cinco deles estrangeiros), incluindo tanto os questionários em papel (aqueles que vão ser depois consolidados nos Anuários Estatísticos na 1. e Seção do Corpo de Cadetes) quanto os dados organizados digitalmente em formato de "tripão", isto é, uma planilha em Excel com muitas colunas de informações sobre cada cadete, incluindo nome, data de nascimento, números de documentos pessoais, informações sobre os pais, local de origem, endereço, características físicas, número de conta bancária, renda da família de origem, se haviam contraído empréstimos bancários etc.

Esse capitão prontamente dispôs-se a nos copiar o arquivo do "tripão" referente à sua companhia, mas antes enfatizamos que não queríamos, de forma alguma, que fosse copiada qualquer informação pessoal como número de documentos, endereços, conta bancária etc., e que queríamos apenas as colunas referentes aos dados socioeconômicos, que nos interessavam de forma anônima. Feita a seleção das colunas, o arquivo foi copiado para nossos dispositivos de armazenagem.

Ao perguntarmos sobre a possibilidade de conseguirmos as informações sobre cadetes de anos anteriores, o capitão nos explicou que eles não guardavam essas informações, pois a cada ano ingressava uma nova turma. Com isso, a turma anterior deixava de estar sob sua responsabilidade, as informações sobre esses cadetes eram deletadas e começava-se a organização de dados apenas sobre o novo grupo que chegava e que, portanto, passava a estar sob seu comando. Disse que não era sua responsabilidade fazer qualquer tipo de análise histórica ou sociológica a respeito desses dados, motivo pelo qual eles não tinham mais utilidade depois que cumpriam sua função. Os dados do ano findo eram então enviados para a 1. ․ Seção do Corpo de Cadetes para serem sistematizados e chegarem à quantificação total dos cadetes do presente ano.

Mais uma vez nos foi dada a informação de que trabalhavam por demanda e que os dados históricos não eram guardados. Esse capitão mostrou-nos ainda uma planilha que resultaria num estudo, "Exército em Números", que estava sendo preparado pelo Comando do Exército.

Desta companhia retornamos, sempre guiados pelo mesmo capitão, para a Coordenação Pedagógica, para falar com o major responsável pela Subseção de Pesquisa, que não estava presente quando de nossa visita. Após falarmos novamente sobre o motivo de estarmos ali, ele nos informou que estava na função havia apenas um ano e meio e que seu trabalho era dificultado pela falta de pessoal: de três oficiais previstos para ali trabalharem, dois haviam sido transferidos, restando apenas ele. Contou que ele foi o responsável pelo envio das informações que recebemos por intermédio do EME, e que só tinha conhecimento desses dados da forma pela qual eles nos foram disponibilizados. Reconheceu que não possuem um banco de dados histórico e disse que estão dando início a uma mudança no sistema de dados utilizados: o atual SIAMAN (Sistema de Informações Acadêmicas da AMAN) teria, em suas palavras, "entrado em colapso" e estaria sendo substituído por uma tecnologia mais moderna, porém ainda sem previsão para entrar em 
funcionamento. Disse esperar que, num prazo de quatro a cinco anos, sua Subseção de Pesquisa pudesse efetivamente começar a fazer pesquisas sobre os dados dos cadetes.

Em seguida, nosso capitão-guia levou-nos à Divisão de Tecnologia da Informação (DTI), responsável pela manutenção do sistema de dados da AMAN. Fomos recebidos pelo coronel chefe, que nos levou para uma sala de reuniões juntamente com dois outros oficiais que lá trabalhavam. Explicamos novamente nossos interesses de pesquisa e mencionamos o convênio com o EME. Em seguida, o coronel e seus colegas nos falaram francamente sobre as dificuldades relacionadas ao uso do banco de dados da AMAN, que segundo eles seria precário e estaria desatualizado. Devido às dificuldades com o banco de dados atual, estariam providenciando um novo modelo de banco de dados, mais moderno e eficiente. Enfatizou que o modo de trabalho do Exército é "com soluções de escritório", respondendo exclusivamente à demanda dos superiores, sem manter uma perspectiva de pesquisa.

Eles explicaram ainda que têm planilhas eletrônicas com as informações socioeconômicas dos cadetes que estão cursando atualmente os quatro anos da AMAN e que possuem também dados desde 1997, embora menos completos. Disseram não ter informações mais detalhadas dos cadetes já formados porque "o próprio sistema apagava" essas informações, mas que o novo sistema, ainda sem perspectiva para entrar em funcionamento, deveria evitar que isso ocorresse. Um tenente-coronel presente à reunião levou-nos então até seu computador e pacientemente editou, ao longo de uma hora, as planilhas de forma que o arquivo que nos fosse copiado incluísse apenas as informações de nosso interesse, excluindo, a nosso pedido, as informações mais pessoais.

É importante enfatizar que todos os nossos interlocutores foram muito solícitos e, na medida de suas capacidades, colaborativos. Não percebemos, de forma alguma, qualquer tentativa de ocultar informações, nem de mascarar a realidade de como os dados eram tratados, incluindo suas dificuldades e precariedades.

Como ficou evidente ao longo da descrição dessa visita, sempre dávamos informações sobre que tipo de dados queríamos e também mencionávamos o convênio com o EME. Esta menção obviamente enquadrava nossa demanda numa cadeia hierárquica de comando, deixando claro que tínhamos autorização de uma instância superior do Exército. Isso não trazia, contudo, nenhuma novidade ou incômodo para os militares com os quais interagimos, integrantes de uma instituição na qual a hierarquia atravessa e ordena todas as atividades cotidianas. ${ }^{9}$ Por outro lado, a menção ao convênio ajudava a explicar que a pesquisa trazia potencialmente interesse para a própria instituição, em particular para o EME, envolvido com as atividades de planejamento do Exército em mais alto nível.

Para nós, ficou evidente que a visita havia sido muito importante para entender melhor a forma pela qual os dados que recebemos eram produzidos e gerenciados. Imediatamente contatamos novamente nosso interlocutor no EME,

9 Sobre as características da pesquisa de campo em instituições militares brasileiras, ver Castro e Leirner (2009). 
solicitando que também agendasse visitas à EsPCEx e à EsSA, para podermos ter um quadro completo a respeito dos dados produzidos por essas escolas de formação.

\section{IV}

Ao chegarmos à Escola Preparatória de Cadetes do Exército, ${ }^{10}$ fomos recebidos por uma tenente, que nos encaminhou para a sala do chefe da Divisão de Ensino, um coronel da reserva/PTTC, ${ }_{11}^{11}$ que nos acompanharia por toda nossa visita. O coronel pediu para a tenente "reunir todo o pessoal" para uma reunião. Fomos em seguida levados a um auditório onde nos aguardavam cerca de 20 oficiais e alguns funcionários civis. Havia coordenadores ou representantes de todas as matérias lecionadas e de todos os setores envolvidos com ensino na escola. O coronel fez então uma pequena apresentação, explicou que reuniu os chefes das seções que seriam afeitas ao projeto e pediu para que eles se apresentassem individualmente.

Para nossa surpresa, havia a expectativa de que faríamos perguntas a serem respondidas pelos presentes, conforme a especialidade de cada um. Ao dirigir-nos aos presentes, apresentamos a pesquisa e mencionamos as dificuldades encontradas na AMAN em relação aos dados referentes à origem social dos oficiais, e que originou o desejo de visitar a EsPCEX. Enfatizamos que essa dificuldade não era devida a uma deficiência do Exército, mas que dizia muito sobre a lógica interna da instituição no que diz respeito ao armazenamento de dados.

Da conversa que se seguiu surgiram indicações de locais da escola onde poderíamos conseguir os dados que buscávamos, como a Divisão de Tecnologia da Informação (DTI) - que teria informações desde 2007 -, a Seção de Concurso, o Corpo de Alunos e a Seção Psicopedagógica. Além disso, disseram que, assim como na AMAN, também teríamos acesso principalmente a dados já agregados. Eles reconheceram que trabalhavam com a mesma lógica pragmática dos oficiais da AMAN, não desenvolvendo pesquisas e tratando os dados de forma segmentada pelas diferentes seções da escola. Disseram ainda que transformavam imediatamente documentos gerados em Word ou Excel para o formato PDF, como forma de evitar que eles fossem alterados ou corrompidos.

Fomos em seguida levados para uma sala com seis oficiais responsáveis pelas seções identificadas como de interesse para a pesquisa. Nessa reunião, os presentes reafirmaram as dificuldades de acesso aos dados, que são destruídos com o passar do tempo, não restando "arquivo morto" ou backup dos dados desagregados. No sistema em uso na escola seria possível achar apenas dados posteriores a 2010, mas eles se prontificaram a disponibilizar todos os dados anteriores que tivessem. A major responsável pela Seção Psicopedadógica nos mostrou o "formulário de anamnese" aplicado aos cadetes. Disse que havia feito uma alteração nas questões

10 As visitas à EsPCEx (12/11/2015) e à EsSA (13/11/2015) foram feitas apenas por Celso Castro e Sílvia Monnerat.

11 Oficiais inativos que são contratados em regime de prestação de tarefa por tempo certo (PTTC). 
relativas à vida familiar do aluno, com o objetivo de ter informações que representassem melhor as variantes familiares encontradas atualmente na sociedade brasileira: se os pais moravam juntos, se eram separados etc. Vale observar que os demais presentes não conheciam esse novo detalhamento do questionário, que acharam interessante. Todos foram muito solícitos e prontificaram-se a nos enviar os dados, o que fizeram algumas semanas depois.

Seguimos para a Escola de Sargentos das Armas, onde, fomos recebidos por um capitão que trabalhava na Divisão de Ensino, responsável por uma subseção de planejamento e pesquisa, que nos levou à sala do tenente-coronel subcomandante, pois o comandante estava em viagem. Este nos perguntou se os dados enviados à FGV via EME não tinham sido suficientes. Enfatizamos a importância de conhecer como os dados eram elaborados, armazenados e utilizados, bem como a necessidade de tentarmos conseguir dados desagregados, motivo pelo qual estávamos visitando a escola.

O subcomandante falou sobre a existência de um "arquivo morto" da instituição, no qual estariam as informações dos alunos ao longo do curso, mas enfatizou que os dados mais antigos e completos estavam apenas em papel e que somente de 2002 em diante havia um material mais "apurado". Entregou-nos em seguida uma compilação de dados referentes ao ingresso dos alunos, feita especialmente para nossa visita. Perguntamos se esses dados também não poderiam ser disponibilizados em versão digital, o que facilitaria a análise dos mesmos. No mesmo momento, o subcomandante acessou seu computador e nos fez uma cópia dos arquivos.

O capitão falou então das dificuldades na tabulação dos dados oriundos de questionários feitos em papel, tanto por falta de pessoal quanto pelo fato de que essas questões não estavam diretamente relacionadas aos objetivos da escola. Sua fala se aproxima muito da que ouvimos nas outras duas instituições visitadas, isto é, de que os dados eram elaborados e armazenados exclusivamente com uma finalidade pragmática e relatórios eram elaborados por demanda de escalões superiores, não havendo uma cultura de armazenamento de dados desagregados em meio digital, sendo eles geralmente apagados depois que cumpriam sua função.

O subcomandante disse em seguida que uma tenente, que era analista de sistemas, havia desenvolvido um sistema no qual esses dados eram acessados e armazenados por mais tempo e com um maior número de informações. Esse sistema, composto pelo SISPB (com informações referentes aos alunos do período básico do curso de formação de sargentos) e pelo SISPQ (referente ao período de qualificação) conteria as informações que estávamos buscando. Essa tenente, contudo, estava de férias e apenas após o seu retorno poderíamos ter acesso a eles.

Fomos então levados para a Divisão de Ensino, onde pudemos conversar com os responsáveis pelas diferentes seções que a compunham a respeito dos dados que nos interessavam. Na seção responsável pelo SISPB, o oficial responsável nos mostrou uma planilha em Excel que equivalia aproximadamente ao "tripão" visto na AMAN - contendo informações detalhadas dos alunos. Ele disse que esses dados eram registrados desde 2006, porém que o sistema só mantinha dados referentes aos últimos seis anos, deletando automaticamente os anos anteriores. Em relação a estes, só seria possível resgatar informações na sua origem - ou seja, no 
quartel em que o aluno fez o período básico. Disseram que isso ocorria por falta de espaço de armazenagem no sistema, fazendo com que os dados mais antigos tivessem que ser deletados. Feita essa explicação, passaram-nos todos os dados disponíveis em formato digital. Explicaram-nos que o foco deles na Divisão de Ensino era nas provas e na classificação escolar dos alunos, motivo pelo qual não realizavam análises do tipo que pretendíamos fazer. Disseram-nos ainda que, assim como na AMAN, também costumavam transformar os arquivos para formato PDF, deletando as tabelas e dados em Excel.

Seguimos para a Seção Psicopedagógica, onde, após mencionarmos a visita à EsPCEx, e a atualização que havia sido feita no item referente à família do aluno, nos pediram para tirar uma cópia do questionário, para eventualmente utilizá-lo. Em relação aos dados produzidos e mantidos na seção, explicaram-nos que eram sigilosos, referentes aos antecedentes dos alunos (podendo constar, inclusive, informações como uso de drogas, tratamentos psiquiátricos etc.), e que por isso, em sua maioria, os dados não eram sequer digitalizados, para evitar um eventual vazamento de informações. Disseram ainda que cada seção tratava de maneira diferente os dados e utilizava diferentes fontes para tal: se a demanda chegasse da Divisão de Ensino, eles buscariam os dados on-line no Lime Survey; se a demanda chegasse da Seção Psicopedagógica, fariam a pesquisa nas fichas dos alunos (em papel); se chegasse do Corpo de Alunos, colocariam os alunos em forma para perguntar e contabilizar as respostas. A inexistência de uma base de dados comum fazia com que cada seção lidasse com a demanda de uma forma diferente.

O último local a ser visitado na EsSA foi a seção responsável pelo SISPQ. Os responsáveis nos mostraram o sistema, enfatizaram que ele era muito semelhante ao SISPB (que já havíamos visto) e explicaram que os dados do período básico seriam atualizados com as informações referentes ao período de qualificação. Disseram também que relatórios mais antigos do SISPQ ou o acesso a informações oriundas de um sistema mais antigo (Net Aluno, que tem dados de 1993 a 2001) poderiam nos ser passados apenas por uma tenente específica, que se encontrava de férias, já que eles conseguiam apenas visualizar, mas não gerar relatórios.

Ao final de nossa conversa, o capitão responsável pela seção falou que seria melhor se pudéssemos mandar nossas demandas com alguma antecedência, pois, disse ele, "a última pesquisa que fizemos foi doída! Tínhamos apenas 48 horas para entregar tudo!" Explicou que tiveram que parar tudo o que estavam fazendo para dar conta de entregar os dados no prazo solicitado. Perguntamos se essa última pesquisa era a da FGV e ele confirmou. Todos rimos, pois eles não sabiam que havíamos sido nós os demandantes das informações, através do EME. Explicamos então que a urgência solicitada não era nossa, mas sim do EME. Eles explicaram que no Exército, quanto mais se desce na hierarquia, mais os prazos diminuem. Ao sairmos da sala, o capitão que nos acompanhava comentou: “Tá vendo? Conforme se desce na hierarquia, aumenta a sinceridade". 
V

O relato detalhado dessas visitas e da experiência que tivemos em localizar e entender como eram administrados os "dados" que buscávamos evidencia algumas questões importantes. Todas elas podem ser entendidas como parte do processo de "construção social dos dados" que mencionamos no início deste artigo.

Ficou claro que não há um sistema centralizado de informações que possa gerar relatórios conforme as demandas específicas. O que ocorre é uma segmentação da produção e da administração dos dados que segue lógicas variadas. Comum a todas elas, temos o objetivo pragmático a que servem: cumprir uma rotina, auxiliar no acompanhamento de uma turma ou atender a demandas superiores - neste caso, tratadas como "missões" que têm que ser cumpridas no prazo solicitado, por mais "doídas" que possam ser. Não há, ficou claro, preocupação com a produção de pesquisas embasadas em análises históricas ou sociológicas desses dados. As pessoas com as quais lidamos nessas visitas achavam interessantes nossas questões de pesquisa, porém diziam que não tinham pessoal qualificado ou em quantidade necessária para abordá-las, ou, mais comumente, que não fazia parte do rol de tarefas ou missões que tinham que cumprir.

O fato de estarmos lá autorizados por uma autoridade hierarquicamente superior era conhecido por todos. Além disso, ficou evidente que muitos conheciam o coordenador da pesquisa, quer apenas de ouvir falar, quer por conhecer algum de seus trabalhos. Celso Castro propositalmente demonstrou, nessas visitas, a familiaridade com várias características da vida militar e a natureza dos dados sobre os quais conversamos. Fomos recebidos sempre com cordialidade e as pessoas com quem conversamos procuraram atender, dentro das suas possibilidades, aquilo que solicitávamos. Algumas vezes demonstraram vivo interesse em conhecer os resultados de nossa pesquisa. Não houve, em momento algum, a percepção de que estariam sonegando alguma informação.

Essa experiência demonstrou a necessidade de continuarmos investigando mais o contexto no qual esses dados são produzidos e geridos, para poder melhor entender o que eles podem dizer (ou não) a respeito do perfil dos militares. Ela abriu, também, a possibilidade de que pudéssemos dar um passo além, propondo ao Exército, alguns meses depois, a adoção de algumas práticas na gestão desse tipo de dados que possam, caso sejam adotadas, facilitar não apenas a pesquisa acadêmica, como também as atividades de planejamento necessárias para a tomada de algumas decisões da própria instituição. Nesse sentido, fomos recebidos, no dia 21/03/2016, pelo chefe do EME e vários de seus subordinados, aos quais Celso Castro expôs os dados obtidos, explicou como eles eram pouco úteis para responder a perguntas mais complexas, e propôs sugerirmos um outro modo de lidar com os dados, bem como a sugestão de um novo questionário comum para as escolas. A recepção foi muito boa, e a proposta foi enviada alguns meses depois. Até hoje, contudo, não houve mais retorno por parte da instituição a esse respeito.

Concluímos, inspirados em uma reflexão de Mary Douglas (1998), enfatizando que os "dados" quantitativos sobre o perfil socioeconômico dos alunos dessas escolas militares (mas, acreditamos, muitos dados do mesmo tipo, de outras 
instituições) são gerados, usados e preservados como resultado de práticas direcionadas a fins imediatos, práticos, portanto numa perspectiva diferente da dos pesquisadores que, como nós, dedicam-se a analisá-los. Não explicitar essa diferença e explorar suas consequências pode gerar o "fetichismo dos dados" que mencionamos no início. A observação etnográfica dessas práticas, por outro lado, permite ver como elas estabelecem princípios seletivos, iluminam certas dimensões da vida da instituição e obscurecem outras.

\section{Referências bibliográficas}

Barros, Alexandre de Sousa Costa (1978), The Brazilian Military. Professional Socialization, Political Performance and State Building, Chicago, The University of Chicago, tese de doutorado.

Becker, Howard (2007), Segredos e Truques da Pesquisa, Rio de Janeiro, Zahar.

Carvalho, José Murilo de (2005), Forças Armadas e Política no Brasil, Rio de Janeiro, Zahar. Castro, Celso (2004 [1990]). O Espírito Militar, Rio de Janeiro, Zahar (2ª . edição revista).

Castro, Celso (1994), "A origem social dos militares: novos dados para uma antiga discussão", Novos Estudos CEBRAP, 37, pp. 225-231.

Castro, Celso, e Piero Leirner (orgs.) (2009), Antropologia dos Militares. Reflexões sobre Pesquisas de Campo, Rio de Janeiro, Editora FGV.

Douglas, Mary (1998), Como as Instituições Pensam, São Paulo, EdUSP.

Garnett, Emma (2015), Making Air Pollution Visible. An Ethnography of Data Practices in a Multi-Disciplinary Public Health Project, Londres, London School of Hygiene \& Tropical Medicine, tese de doutorado, DOI: 10.17037/PUBS.02837743

Peirano, Mariza (2014), “Etnografia não é método", Horizontes Antropológicos, Porto Alegre, 20 (42), pp. 377-391.

Stepan, Alfred (1971), The Military in Politics. Changing Patterns in Brazil, Princeton, Princeton University Press.

Celso Castro. Professor da Escola de Ciências Sociais da Fundação Getulio Vargas (FGV CPDOC). E-mail: celso.castro@fgv.br

Silvia Monnerat. Professora colaboradora da Escola de Ciências Sociais da Fundação Getulio Vargas (FGV CPDOC). E-mail: silvia.monnerat@fgv.br

Receção: 09 de janeiro de 2018 Aprovação: 05 de abril de 2018 